\title{
Use of Tongs as Occlusion Plane Guide for Midface Distractor Placement
}

\author{
Madhubari Vathulya ${ }^{1}$ \\ ${ }^{1}$ Department of Burns and Plastic Surgery, All India Institute of \\ Medical Sciences, Rishikesh, Uttarakhand, India
}

Indian J Plast Surg 2019;52:362-363

We describe the use of tongs that are part of regular kitchenware as occlusal plane guide. To use them, after the relevant scalp incisions are made along with periosteal and temporalis muscle reflection, LeFort III osteotomy is done. The normal dental occlusal plane is placed and it is adjusted according to the mandibular or the palatal planes ( - Fig. 1). Then the tongs are placed with each of the flanges on either side of the face, the plane of the flange being parallel to the decided axis of the occlusal plane ( $\boldsymbol{- \text { Fig. }}$ 2). Reference lines are drawn with a

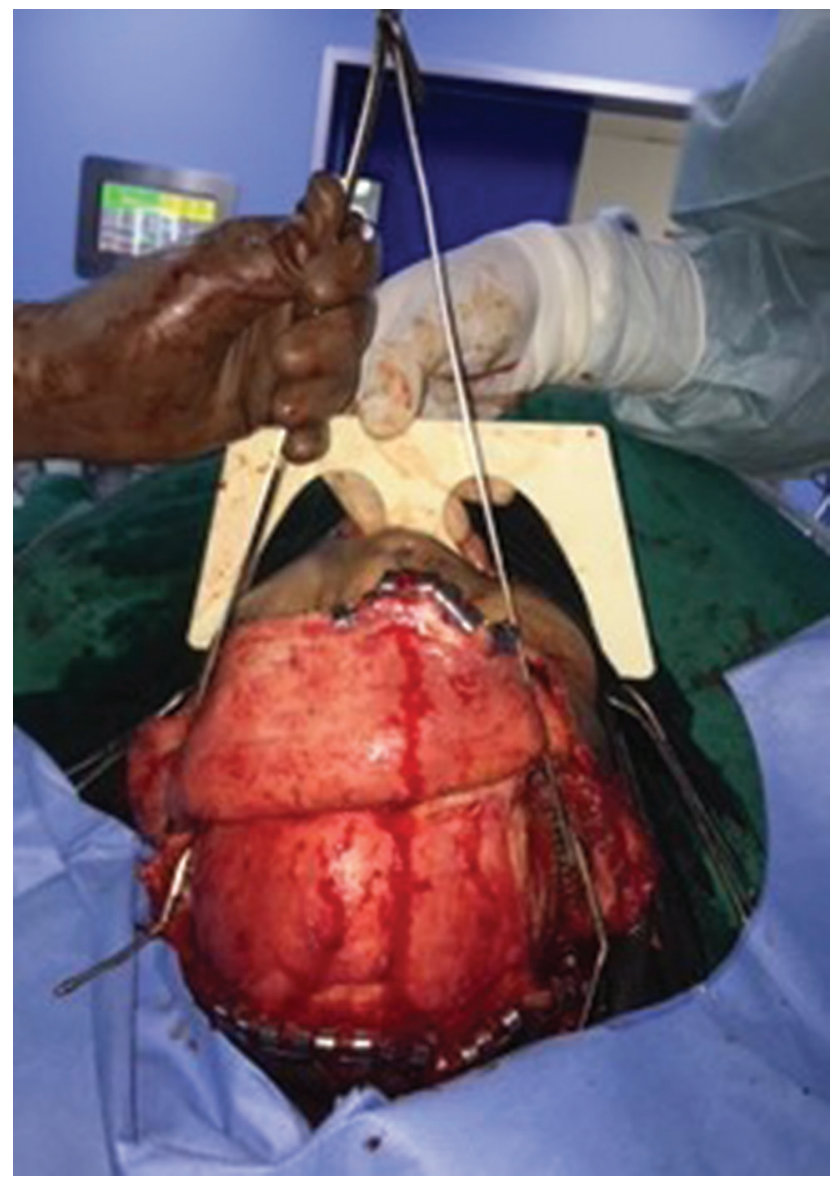

Fig. 1 The dental occlusal plane guide used in the required axis.
Address for correspondence Madhubari Vathulya, MS, MCh, Department of Burns and Plastic Surgery, All India Institute of Medical Sciences, Rishikesh, Uttarakhand, India (e-mail: madhubari@yahoo.co.in).

marking pen on the bone and then the distractors are placed, the foot plate being in the zygomatic region and the posterior segment over the thickest part of the temporal bone.

The main aim of midface distraction ${ }^{1}$ in conditions such as Aperts and Crouzon is to achieve increased orbital depth ${ }^{2}$ and occlusion $^{3}$ simultaneously. The most important factor determining the success of this surgery is the vector of distraction.

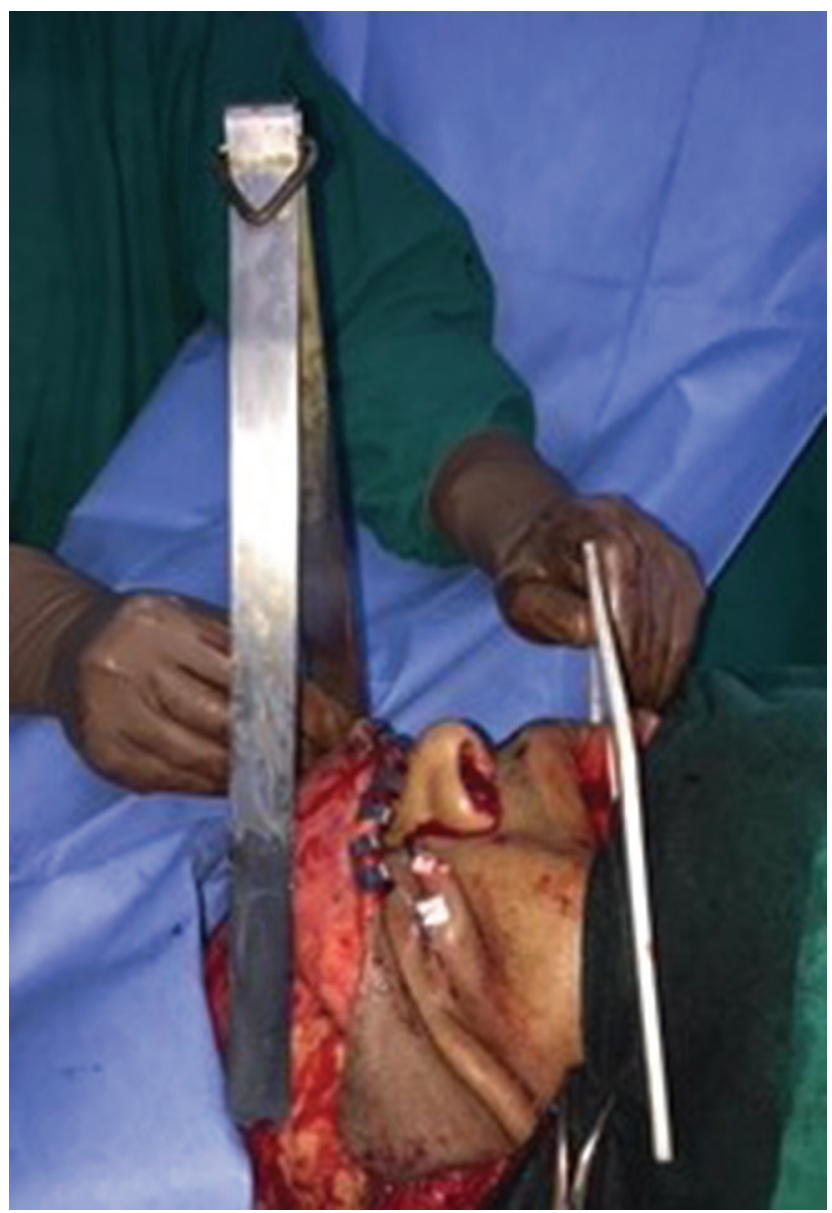

Fig. 2 Tongs being used in a plane parallel to the required dental occlusal axis to decide on placement of the distractors. published online

December 26, 2019
DOI https://doi.org/

10.1055/s-0039-3401524

ISSN 0970-0358. 
The vector of distraction is predominantly decided preoperatively using cephalometric analysis along with the occlusal planes of the patient already existing and the plane which is desired. A few tools such as horseshoe-shaped occlusal planes in the past have been used in aiding the same step. In an axis parallel to the decided occlusal axis, the distractors are then placed using the surgeon's judgement. The usage of this results in some error in judgement while placing the device on both sides. The distractors may have a parallax with respect to each other. So, the surgeons then came up with further occlusal guides ${ }^{4}$ that can be lines derived cephalometrically or very costly instruments that are biflanged to help combat the problem. These are generally used conjointly with occlusal plane devices.

Tongs are biflanged tools welded at the middle. Any degree of abduction or adduction on one of the flanges produced simultaneous deformation of the other. This helps to keep the modifications bilaterally same. The other important aspect is that the site at which the flanges are welded together at the center does not allow any torque to act upon, and hence the flanges are at the same plane no matter how much they are expanded (withdrawn from each other) or collapsed (brought near each other). This ensures that the plane and the height at which the axis of the midface distractor is proposed parallel to the occlusal plane are in symmetry with that of the opposite side.

\section{Conflicts of Interest}

None declared.

\section{References}

1 Al-Namnam NMN, Hariri F, Rahman ZAA. Distraction osteogenesis in the surgical management of syndromic craniosynostosis: a comprehensive review of published papers. Br J Oral Maxillofac Surg 2018;56(5):353-366

2 Alyamani A, Kessler P, Abuzinada S. Management of exorbitism using midface distraction osteogenesis. J Maxillofac Oral Surg 2012;11(1):119-124

3 Kuroda S, Watanabe K, Ishimoto K, Nakanishi H, Moriyama K, Tanaka E. Long-term stability of LeFort III distraction osteogenesis with a rigid external distraction device in a patient with Crouzon syndrome. Am J Orthod Dentofacial Orthop 2011;140(4):550-561

4 Sadr K, Sadr M. A study of parallelism of the occlusal plane and ala-tragus line. J Dent Res Dent Clin Dent Prospect 2009;3(4):107-109 